\title{
FROM EGYPTIAN DESERT TO SCOTTISH HIGHLANDS - THE RADIOGRAPHIC STUDY OF A TWENTY-FIFTH DYNASTY COFFIN AND MUMMY BUNDLE FROM THE PERTH MUSEUM AND ART GALLERY, SCOTLAND
}

\author{
Lidija M. McKnight, Robert D. Loynes \\ KNH Centre for Biomedical Egyptology, \\ University of Manchester, Manchester, UK
}

\begin{abstract}
Since 1936, the Perth Museum and Art Gallery, Scotland, has curated a wrapped ancient Egyptian human mummy within a wooden anthropoid coffin. In June 2013, funding was procured to transport the mummy and coffin to the University of Manchester for radiographic study, whereby information regarding the life and death of the individual was sought.

The mummy and coffin were imaged using digital radiography (DR) and computed tomography (CT) at the Royal Manchester Children's Hospital. The process revealed that the bundle contained the mummified remains of a single human individual, which had suffered extensive skeletal disruption. This paper focuses on the radiographic analysis of the artefact.
\end{abstract}

Keywords: mummy, coffin, imaging, DR, CT

\section{INTRODUCTION}

Perth Museum and Art Gallery, Scotland, curates an ancient Egyptian wooden, bivalve anthropoid coffin to which is applied a cartonnage layer (a linen layer over which gesso is applied) (3) decorated with funerary motifs and inscriptions. The name of a female individual, ta-kr-Hb, was legible on the coffin lid, although no titles were visible due to a layer of organic detritus covering the 
inscription (pers. comm. - C. Price). Iconography dated the coffin to the $25^{\text {th }}$ Dynasty (c. 747-656BC) and was thought to originate from the Akhmim region, Upper Egypt (pers. comm. - A. Dodson, A. Williams, J. Taylor and C. Sheikholeslami).

Lying within and affixed to the coffin base was a wrapped mummy bundle (Fig. 1). Museum records stated that both were donated to the museum in 1936 when the Alloa Society of Natural Science and Archaeology disbanded. The Society received it on $5^{\text {th }}$ May 1896 from a Mr William Bailey, who procured it from the Curator of the Government Museum in Cairo. Archival documents state that it was discovered a few years prior to this acquisition date in Thebes and contained the remains of a priestess or princess of the Late New Kingdom. Other than this, no research was conducted on either the coffin or the mummy, which instigated fresh interest.

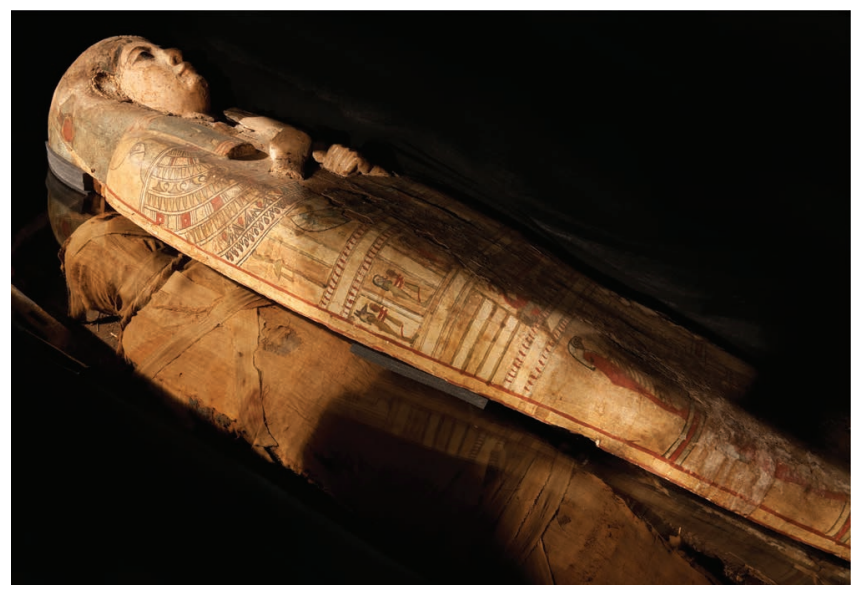

Figure 1. Photograph of the Perth mummy and coffin (image courtesy Perth Museum and Art Gallery).

\section{MATERIALS AND METHODS}

The mummy and coffin were located in 2012 during data acquisition for the Ancient Egyptian Animal Bio Bank project at the KNH Centre for Biomedical Egyptology, University of Manchester (2). At this time, research was delayed pending the procurement of funding to enable specialist transportation of the artefact. In June 2013, following a successful funding bid, the mummy and coffin were transported to Manchester in bespoke conservation crates for imaging analysis.

The imaging investigation took place at the Royal Manchester Children's Hospital and comprised a macroscopic overview including epigraphic and iconographic assessment. Digital radiographs (DR) were obtained on a Philips 
Eleve Digital Diagnostic machine producing overlapping images in two projections (antero-posterior and lateral), which were later joined using computer algorithms. Computed tomography (CT) (Somatom Definition AS+ (Siemens Medical Systems, Germany) was conducted giving a slice thickness of $0.625 \mathrm{~mm}$ and producing over 6800 transverse axial images. The coffin base and mummy bundle were imaged together as the bundle appeared to be firmly fixed. The coffin lid was studied separately using both imaging modalities.

\section{RESULTS}

\section{Macroscopic Overview}

The coffin was in excellent condition with a localised area of damage to the footboard of the base. A patchy, hardened layer of extraneous detritus, under which the decoration was discernable, was noted on the coffin lid.

An initial assessment of the mummy bundle revealed a complete and wellpreserved example wrapped in plain brown linen. A linen shroud covered the entire length of the bundle (Fig. 2). A single twisted linen strip, almost 'ropelike' in appearance, was present around the neck. The linen wrappings over the head were slightly disturbed, which uncovered a small patch of the skull vault. Narrower self-coloured linen strips were present although they appeared disturbed from their original placement: down the centre line of the body, crossed over the chest and horizontally around the legs (Fig. 2). The feet suffered more serious disruption with the removal of the bandages prior to being rewrapped in a haphazard manner. Detailed examination of the coffin interior highlighted the presence of skeletal fragments lying loose within the base, although their origin was not visible macroscopically.

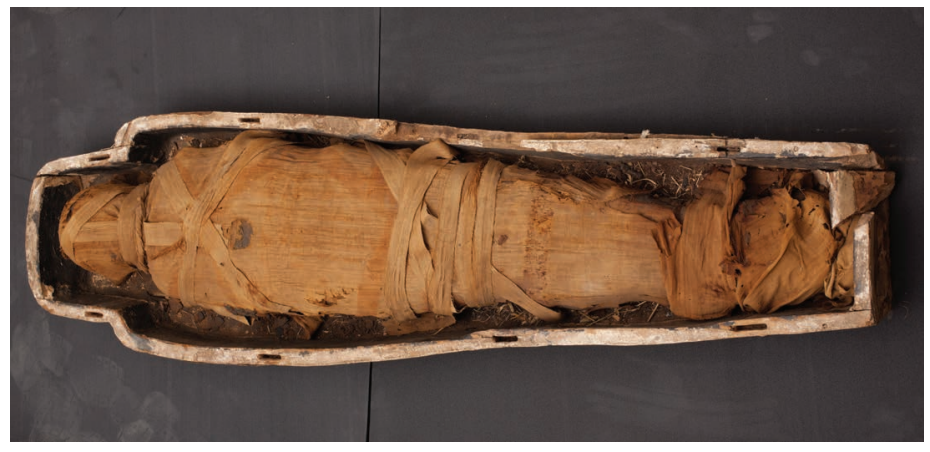

Figure 2. Photograph of the linen shroud covering the mummy bundle (image courtesy Perth Museum and Art Gallery). 


\section{Radiographic Investigation of the Coffin}

Imaging of the wooden anthropoid coffin showed that the base was constructed from three wooden planks fastened with what was thought to wooden dowels (Fig. 3). A gap was revealed between two of the planks used in the construction, through which loose matter was being lost. The damaged area of the footboard was highlighted. The coffin lid demonstrated moulded facial features, a wig and grasped, individual hands placed above one another. The gesso applied to the exterior of the coffin appeared as a radiodense material, particularly visible in the joints.
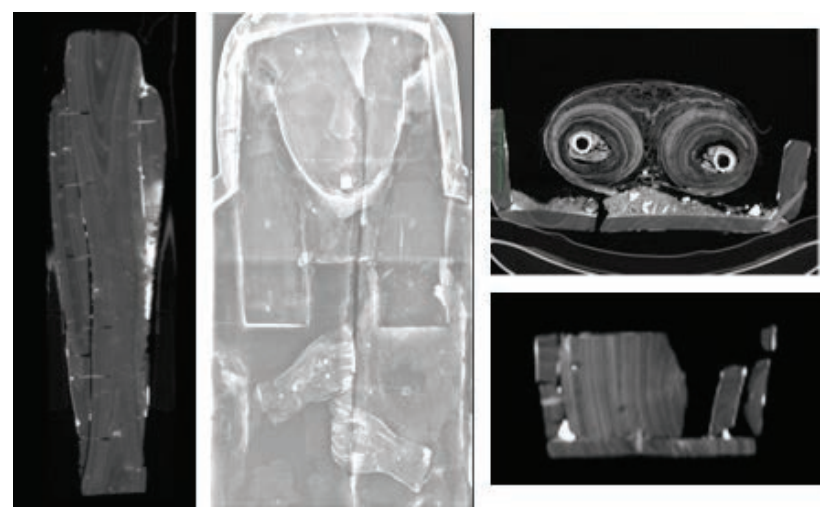

Figure 3. Coronal reformat showing the construction of the coffin base; DR image of the coffin lid showing the facial features, wig and clasped hands; transverse axial image showing the gap between the wooden planks through which loose matter is being lost; and sagittal reformat of the footboard showing the area of damage (image courtesy University of Manchester and Perth Museum and Art Gallery).

\section{Radiographic Investigation of the Mummy Bundle}

Imaging of the mummy bundle showed the presence of a single human individual. The skull was largely intact; however, the thorax, pelvis and lower limbs suffered extensive post-mortem damage leading to skeletal disruption and displacement (Fig. 4). 

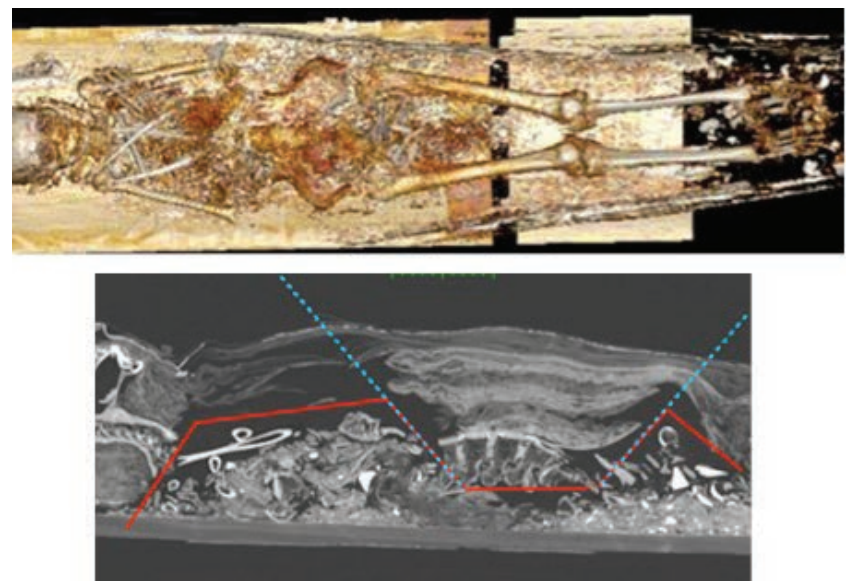

Figure 4. 3D and sagittal reformats showing the extent of the damage to the skeleton and sagittal reformat showing the flexion points of the mummy bundle (image by Robert Loynes, University of Manchester).

Coffin iconography suggested the gender of the occupant to be female; however, disruption to the pelvis and perineum along with the presence of non-prominent brow ridges, made accurate sex estimation equivocal. Age estimation, based on skeletal development, suggested an adult individual. Dental attrition and severe alveolar recession with subsequent remodelling of the maxillary bone indicated that the individual was most likely over 35 years (Fig. 5).
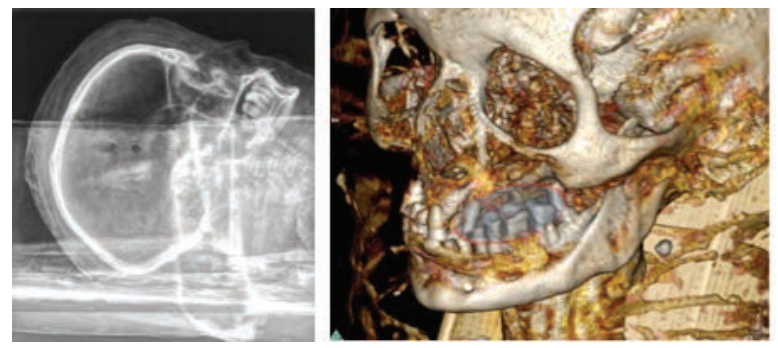

Figure 5. Lateral DR image and oblique reformat showing the recession of the maxillary alveolar as a result of excessive dental wear (image courtesy University of Manchester).

The skull demonstrated complete trans-nasal excerebration via the ethmoid sinus, whilst the sphenoid sinus remained intact. The orbits were packed with fabric, thought to be linen, overlying the desiccated orbital matter (Fig. 6). The tongue and larynx were preserved in situ with no evidence of packing within the mouth or neck. The mandible appeared slightly protrusive, although the condylar heads were articulating with the mandibular fossae. In addition, one molar appeared to lie displaced in the AP plane, thought to be a post-mortem artefact as opposed to an anatomical feature. 


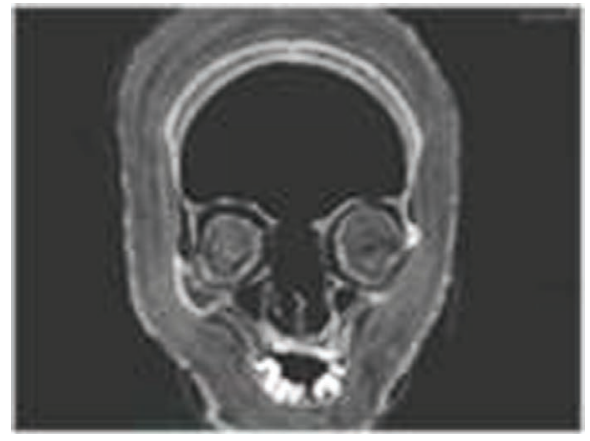

Figure 6. Coronal reformat of the skull showing the packing within the orbits (image courtesy University of Manchester).

The head and neck were separated from the trunk through the body of the second thoracic (T2) vertebra. The thorax was completely destroyed and only three thoracic vertebrae appeared in continuity. The spinal column was intact from the first cervical vertebra to the upper border of $\mathrm{T} 2$. The innominate bones and sacrum were positioned in approximately the correct anatomical position; however, it was not possible to assess whether evisceration was practiced due to the extent of the damage. The upper limbs showed disruption consistent with that of the torso through the presence of multiple fractures.

The pelvis and both femoral heads were fractured; however, these appeared inconsistent with ante-mortem injury. In the left femur, the fracture continued across the top of the femoral head, and in the right through the femoral neck inferiorly through the calcar, which was characteristic of post-mortem fractures in archaeological bone (Fig. 7).

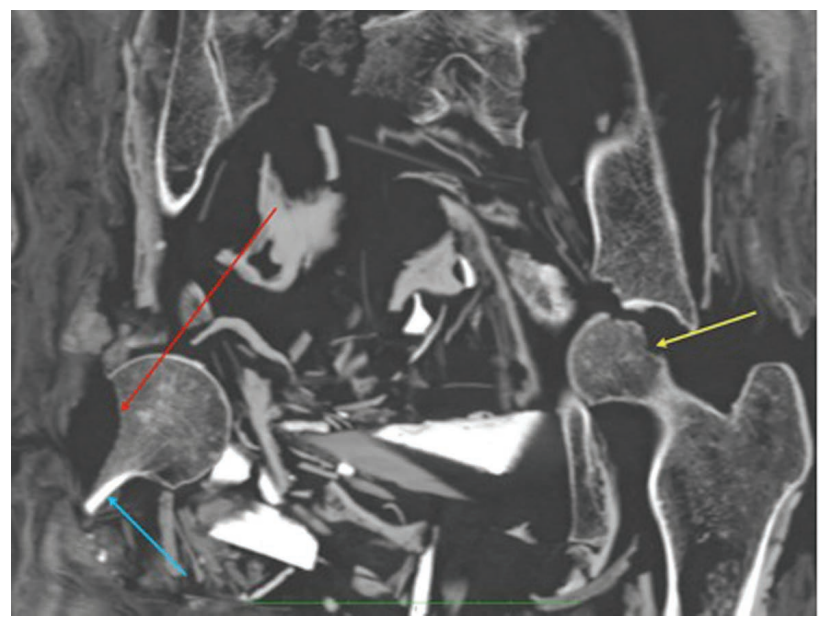

Figure 7. Reformat showing extensive fractures to the pelvic region: Upper part of the left femoral head (yellow arrow); upper part of the right femoral head (red arrow) and the femoral neck running inferiorly through the calcar (blue arrow) (image by Robert Loynes, University of Manchester). 
The left patella demonstrated an abnormal appearance characterised as a density within the bone (Fig. 8); however, this was interpreted as a possible dense bone island or, less likely, the result of osteopoikylosis, a benign systemic condition caused by an autosomal dominant gene (4). The left tibia demonstrated a fracture to the upper aspect with posterior dislocation of the tibia from the lower femur (Fig. 8). Both feet were detached from the tibiae and the left fibula was absent.

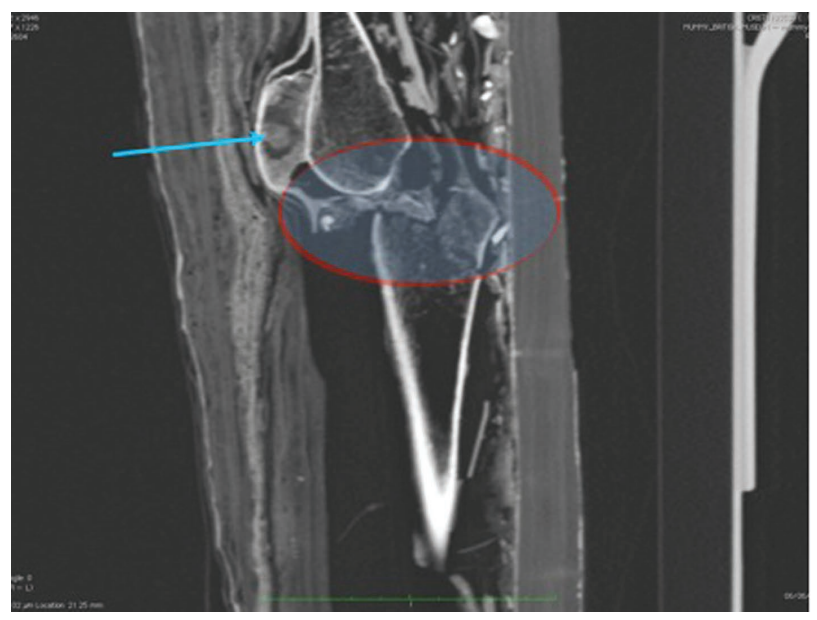

Figure 8. Sagittal view showing the anomaly in the left patella thought to have been caused by a dense bone island or osteopoikylosis (blue) and the displaced fracture of the tibia (red) (image by Robert Loynes, University of Manchester).

The wrapping technique appeared relatively thick over the skull and cervical region (Fig. 6). The visualisation of air voids between the bandages and the desiccated tissue in the thoracic region showed that the left arm was once positioned on the right shoulder, which mirrored the in situ position of the right hand on the left shoulder (Fig. 9). The upper arms remained attached to the bandages in an event that caused the humeri to fracture at the distal ends. The limbs were individually wrapped in linen, before being bound together during the final stages of the mummification process.
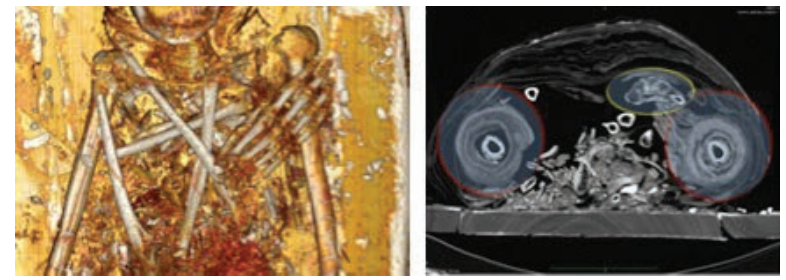

Figure 9. 3D reformat and axial image showing the placement of the individually wrapped arms (red) and hands. The right carpus appears close to the left shoulder (yellow) (image by Robert Loynes, University of Manchester). 


\section{DISCUSSION}

\section{Macroscopic}

The wrapping style of the mummy bundle indicated similarities with the Middle Kingdom to Late Period based upon the individually wrapped limbs, the anatomical position and the presence of the linen bands applied to the exterior of the wrapped bundle (1). This date was consistent with the date of the $25^{\text {th }}$ Dynasty for the coffin. The twisted band of linen placed around the neck of the bundle may represent the means by which the body was lowered into the coffin base after completion of the embalming procedure. The damage to the wrappings was consistent with an attempt to remove the mummy bundle from the coffin (Fig. 2).

\section{Radiographic}

Imaging established that although the exterior of the mummy bundle was wellpreserved, the interior was not so. Damage to the skeletal remains suggested that the mummy bundle was subjected to vigorous disruption at some point post-wrapping. The damage was consistent with the simultaneous lifting of the head and feet of the mummy bundle (Fig. 4). This resulted in the upper portion of the body being lifted whilst the lower portion remained fixed to the coffin base, most likely due to the presence of the visible adhesive substance, thought to be resinous in origin. The interior layers of wrappings fractured along with the body, yet the outer layers remained sufficiently supple to flex with the action and remain intact, giving the outward impression of a well-preserved bundle. The fractured inner layers suggested the use of resinous substances on the body and as adhesive between the layers, which desiccated and resulted in a brittle fabric. The body flexed at the second lumbar (L2), which caused the left hand to become detached from the right shoulder and fall posterior to the thorax. Although the linen wrappings would have flexed with the intervention, the skeletal remains fractured at T2 level, which caused the thorax and forearms to collapse and led to the extensive disruption witnessed radiographically. It is suggested that the left fibula was removed or lost from the bundle during the attempted unwrapping of the feet.

It is possible that the damage was caused by grave looters searching for amulets or jewellery placed on and within the linen wrappings, or at least in an attempt to remove the body from the coffin. It is possible that the damage occurred during the export of the mummy and coffin from Egypt, or as the result of museum curation practices. The chronological placement of the intervention is unknown; however, the damage to the skeletal remains suggests 
that the tissues were completely desiccated by this point so were likely to have occurred post-interment.

Imaging highlighted areas of the coffin and mummy bundle which require remedial conservation work, such as the gap between the wooden planks making up the coffin base (Fig. 3), to consolidate and stabilise the artefact prior to its future display.

\section{CONCLUSION}

In conclusion, imaging of the Perth mummy demonstrated a poorly preserved individual encased within a well-preserved mummy bundle. Iconographic and epigraphic investigation suggested that it was unlikely to have originated from the Theban region, instead indicating similarities to Akhmim. Many artefacts from the cemeteries of Akhmim were sold through the Cairo Museum during the early 1890s, which was consistent with the acquisition date recorded in the museum archives. Unfortunately, there was little indication that the individual was either a princess of priestess.

The research and subsequent conservation recommendations will enable the mummy and coffin to be displayed publically at Perth Museum and Art Gallery for the first time since it was removed from the galleries in the 1970s. It is hoped that the removal of the layer of debris from the exterior of the coffin will enable the hieroglyphs to be further interpreted to shed light on the individual, her familial ties and her position in ancient Egyptian society. Further scientific investigation is planned to analyse the pigments used in the decoration of the coffin and the substances used in the preservation of the body.

\section{ACKNOWLEDGEMENTS}

The authors would like to express their gratitude to Mark Hall, History Officer at Perth Museum and Art Gallery, for his support of the project. To John Taylor, Alison Williams, Aidan Dodson and Cynthia Sheikholeslami for their insights on the iconography and provenance of the artefact. To Dr Campbell Price for his epigraphic evaluation and Dr Roger Forshaw for his interpretation of the dental images. Grateful thanks go to Professor Judith Adams, Consultant Radiologist, Central Manchester Teaching Hospitals NHS Foundation Trust, and her team of radiographers for their time and assistance. To the Faculty of Life Sciences, University of Manchester, for the provision of the Career Development Award which allowed the artefact to be transported safely to Manchester for study. 


\section{REFERENCES}

1. Ikram S., Dodson A. (1998). The Mummy in Ancient Egypt: Equipping the Dead for Eternity. Thames and Hudson. London.

2. McKnight L. M., Atherton S. D., David A. R. (2011). Introducing the Ancient Egyptian Animal Bio Bank at the KNH Centre for Biomedical Egyptology, University of Manchester. Antiquity Project Gallery 85, 329.

3. Nicholson P. T., Shaw I. (2000). Ancient Egyptian Materials and Technology. Cambridge University Press. Cambridge.

4. Renton P. (1990). Orthopaedic Radiology: Pattern Recognition and Differential Diagnosis. Year Book Medical Publishers. London.

\section{Address for correspondence:}

Dr Lidija M. McKnight

KNH Centre for Biomedical Egyptology

University of Manchester

3.503 Stopford Building

Oxford Road, Manchester M13 9PT

UK

E-mail: lidija.mcknight@manchester.ac.uk 